\title{
NECESSITY OF BUDGET DEFICIT UNDER ECONOMIC GROWTH IN MONOPOLISTIC COMPETITION
}

\author{
Yasuhito TANAKA \\ Doshisha University, Kyoto, Japan \\ Corresponding author e-mail: yatanaka@mail.doshisha.ac.jp
}

\begin{abstract}
The aim of the paper is to show, using a simple two-period overlapping generations model in which goods are produced solely by labour in a monopolistically competitive industry, that a continuous budget deficit (including the interest payments on government bonds) is necessary to achieve and maintain full employment under economic growth driven by technological progress. Since the budget deficits must be continuous, it might be better if they were financed by seigniorage rather than government debt. Since the budget deficit due to the issuance of government bonds puts pressure on fiscal expenditures in the amount of interest payments, a budget deficit of the same size due to seigniorage is a more effective use of the budget. It will also be shown that to achieve full employment from a recession with involuntary unemployment the extra budget deficit is necessary.
\end{abstract}

Keywords: Budget deficit, Economic growth, Government bonds, Overlapping generations model, Seigniorage.

JEL Classification: E12, E24

\section{INTRODUCTION}

Although the accumulation of government debt has become a problem in many countries in recent years, this paper argues that the accumulation of government debt is an inevitable and natural phenomenon in a growing economy and should not be considered a problem.

Using a simple two-period overlapping generations model in which goods are produced solely by labour in a monopolistically competitive industry, the author will show that a continuous budget deficit (including the interest payments on government bonds) is necessary to achieve and maintain full employment under economic growth driven by technological progress. In this paper, savings are assumed to be made in the form of government bonds, not money, and the government bonds yield interest income*. Since the budget deficits must be continuous, it might be better if they were financed by seigniorage rather than

\footnotetext{
* In some other papers the author analysed budget deficit in a growing economy in several settings, for example, a simple macroeconomic model without microeconomic foundation about consumers and firms, a static (non-overlapping generation) model and an overlapping generation model under perfect competition and those under monopolistic competition. In almost all of these analyses, however, savings are made in the form of money, and no interest is generated. In (Tanaka, 2022) the author analyses a problem of the longrun value of the debt-to-GDP ratio under monopolistic competition. It is shown that the debt-to-GDP ratio approaches a finite value over time at least in a case of economic growth by technological progress.
} 
government debt. It will also be shown that to restore full employment from a recession with involuntary unemployment extra budget deficit is necessary.

If the interest rate of the government bonds is set to be zero, the budget deficit due to government bonds is practically the same as the budget deficit due to seigniorage. Note that, as will be discussed in Section 3.2, if the interest rate of the government bonds is larger than the economic growth rate, the budget deficit excluding interest payments which is necessary and sufficient to maintain full employment may be negative. Since the budget deficit due to the issuance of government bonds puts pressure on fiscal expenditures in the amount of interest payments, a budget deficit of the same size due to seigniorage is a more effective use of the budget. Also, the interest on government bonds can be regarded as a kind of benefit policy for bondholders, and a sense of unfairness cannot be avoided. Therefore, only the interest portion of the budget deficit caused by the issuance of government bonds is considered to be borne by the general public. In order to use fiscal expenditure effectively, it is better to use seigniorage instead of government bonds.

This paper can be considered as one of the attempts to provide a theoretical foundation for Functional Finance Theory (Lerner, 1943; Lerner, 1944) and Modern Monetary Theory (MMT) (Kelton, 2020; Wray, 2015; Mitchell, Wray, and Watts, 2019). In our opinion, the essence of MMT argument is the following two points.

1. Fiscal spending does not require financial resources, and taxes are not a source of revenue for fiscal spending.

From a macroeconomic perspective, fiscal spending increases demand for goods, while taxes decrease demand by reducing consumers' disposable income. In order to achieve and maintain stable growth under full employment without inflation, an appropriate balance between the size of fiscal expenditure and taxation is necessary, and taxation is not necessary to finance fiscal expenditure ${ }^{\dagger}$.

2. There is no need to pay off the national debt with taxes.

If it wanted to, the central bank could buy up all government bonds. That may have the effect of lowering interest rates, but since it does not increase people's assets or income (unless the central bank buys up government bonds at a price above face value), it does not directly increase demand for goods and thus does not cause high inflation. If implemented during a recession, it will not cause low inflation either. Government bonds are money in the broad sense of the term, just as bank time deposits are ("liquidity in the broad sense"), and the central bank's purchase of government bonds does not increase the money supply in that sense, so it does not cause inflation even from the standpoint of the quantity theory of money.

This paper also provides an argument for the following claim (Kelton, 2020). The author refers here to Hogan's summary of Kelton's book (Hogan, 2021). In fact,

$\dagger$ The main reason for targeting full employment is that high unemployment brings with it a variety of social and economic costs. First, the unemployed have low income, which enables them to consume at low levels. This low income leads to relative poverty. In addition, the skills of the unemployed may be reduced. Job training is important for employers. Unemployed people who have no money to spend on training and are unable to work create a negative cycle that makes it harder for them to find work in the future. The longterm unemployed have the most difficulty in finding work. 
Hogan criticises Kelton, but he summarises the main points of the argument in a good way.

3. The US Treasury creates new money.

Since consumers save with money (including government bonds), and since money supply equals savings, an increase in money supply equals an increase in savings. The increase in savings equals the budget deficit. Since the rate of increase in savings equals the rate of increase in money, which equals the rate of economic growth, i.e., the rate of increase in the production of goods, the increase in the money supply does not cause inflation.

4. Inflation is caused by federal government deficit spending, not by policy of Federal Reserve Board.

If the actual budget deficit is larger than the budget deficit necessary and sufficient to maintain full employment in a growing economy, the price of goods will rise (see Section 3.3).

5. Federal government spending is not related to taxes or borrowing.

In order to achieve full employment under economic growth, a sustained budget deficit is necessary. Under economic growth, it is impossible to maintain full employment through a balanced budget. Therefore, even if the budget deficit to maintain full employment is financed by government bonds, there is no need to cover them with future budget surpluses. The same is true for the additional budget deficits needed to eliminate involuntary unemployment caused by inadequate budget deficits and return to full employment.

The relationship between budget deficits and economic growth has been analysed in (Otaki, 2012; Otaki, 2013; Otaki \& Tamura, 2013) ${ }^{\ddagger}$. In particular, Otaki \& Tamura (2013), using an endogenous growth model with cost reducing investment, states that the budget deficit is necessary for economic growth, and the debt-to-GDP ratio increases because cost reducing investment reduces labour demand under monopolistic competition. However, he seems to believe that the government debt must be paid off with taxes. "It is unavoidable that the issuance of public debt impairs the welfare of future generation even in a Keynesian framework" (Otaki, 2015b). This is where the author disagrees especially in a situation of underemployment. The author believes that when government bonds are issued, only the amount of interest paid to bondholders will be borne by the public.

The next section, using calculations in Appendix, presents analyses of behaviour of consumers and firms. In Section 3, the necessity of budget deficit to achieve and maintain full employment under economic growth will be discussed. In Section 4, the role of extra budget deficit to restore full employment from recession will be shown. In Appendix, the author presents calculations about utility maximization of consumers and fiscal spending by the government.

\footnotetext{
$\$$ They are summarised in Otaki (2015a).
} 


\section{THE MODEL}

There is a two-period (1: younger or working, and 2: older or retired) overlapping generation (OLG) model under monopolistic competition. Our model is according to Otaki (2007), Otaki (2009) and Otaki (2015a), and a generalization of Tanaka (2020), in which perfect competition is assumed. The structure of our model is as follows.

1. There is one factor of production, labour, and there is a continuum of perishable goods indexed by $z \in[0,1]$. Good $z$ is monopolistically produced by firm $z$ with constant returns to scale technology. The technology progresses at the rate $\gamma-1>0$.

2. During Period 1, each consumer supplies 1 unit of labour, consumes the goods and leaves savings for their future consumption. Consumer is employed or not employed. Savings are assumed to be made in the form of government bonds, not money, and the interest rate of the bonds is denoted by $r>0$.

3. The utility of an employed consumer is larger than the utility of an unemployed consumer, including labour disutility.

4. During Period 2, each consumer consumes the goods using the savings carried over from Period 1 earnings plus interest income on government bonds.

5. Each consumer determines the consumption in Periods 1 and 2 at the beginning of Period 1 depending on the situation whether the consumer is employed or not.

The following notation is used:

$C_{i}^{e}$ : consumption basket of an employed consumer in Period $i, i=1,2$. It is defined in (1).

$C_{i}^{u}$ : consumption basket of an unemployed consumer in Period $i, i=1,2$. It is defined in (2).

$c_{i}^{e}(z)$ : consumption of $\operatorname{good} z$ of an employed consumer in Period $i, i=1,2$.

$c_{i}^{u}(z)$ : consumption of good $z$ of an unemployed consumer in Period $i$, $i=1,2$.

$P_{i}$ : the price of consumption basket in Period $i, i=1,2$. It is defined in (3).

$p_{i}(z)$ : the price of $\operatorname{good} z$ in Period $i, i=1,2$.

$\rho=P_{2} / P_{1}:$ (expected) inflation rate (plus one).

$W$ : nominal wage rate.

$\Pi$ : profits of firms that are equally distributed to younger generation consumers.

$L:$ total employment.

$L_{f}$ : population of labour or employment in the full employment state.

$y$ : labour productivity, which increases by technological progress.

It is assumed that the population $L_{f}$ is constant. 


\section{BEHAVIOUR OF AGENTS}

\subsection{Consumers' Behaviour}

The utility function about consumption of an employed consumer of one generation over two periods is written as follows: $u\left(C_{1}^{e}, C_{2}^{e}\right)$.

$u(\cdot)$ is a homothetic utility function. The utility function of an unemployed consumer is as follows: $u\left(C_{1}^{u}, C_{2}^{u}\right)$.

The consumption baskets of employed and unemployed consumers in Period $i$ are as follows:

$$
C_{i}^{e}=\left(\int_{0}^{1} c_{i}^{e}(z)^{\frac{\sigma-1}{\sigma}} d z\right)^{\frac{\sigma}{\sigma-1}}, i=1,2
$$

and

$$
C_{i}^{u}=\left(\int_{0}^{1} c_{i}^{u}(z)^{\frac{\sigma-1}{\sigma}} d z\right)^{\frac{\sigma}{\sigma-1}}, i=1,2
$$

$\sigma$ is the elasticity of substitution among the goods, and $\sigma>1$.

The price of consumption basket in Period $i$ is as folllows:

$$
P_{i}=\left(\int_{0}^{1} p_{i}(z)^{1-\sigma} d z\right)^{\frac{1}{1-\sigma}}, i=1,2
$$

The budget constraint for an employed consumer is as follows:

$$
\int_{0}^{1} p_{1}(z) c_{1}^{e}(z) d z+\frac{1}{1+r} \int_{0}^{1} p_{2}(z) c_{2}^{e}(z) d z=W l+\Pi .
$$

$l$ denotes the labour supply of an employed consumer. The budget constraint for an unemployed consumer is as follows:

$$
\int_{0}^{1} p_{1}(z) c_{1}^{u}(z) d z+\frac{1}{1+r} \int_{0}^{1} p_{2}(z) c_{2}^{u}(z) d z=\Pi .
$$

Let $\alpha=\frac{P_{1} C_{1}^{e}}{P_{1} C_{1}^{e}+\frac{1}{1+r} P_{2} C_{2}^{e}}, 1-\alpha=\frac{\frac{1}{1+r} P_{2} C_{2}^{e}}{P_{1} C_{1}^{e}+\frac{1}{1+r} P_{2} C_{2}^{e}}$.

Since the utility functions $u\left(C_{1}^{e}, C_{2}^{e}\right)$ and $u\left(C_{1}^{u}, C_{2}^{u}\right)$ are homothetic, $\alpha$ is determined by the relative price $\frac{P_{2}}{P_{1}}$ and the interest rate $r$, and does not depend on the income of the consumers. Therefore, $\alpha=\frac{P_{1} C_{1}^{e}}{P_{1} C_{1}^{e}+\frac{1}{1+r} P_{2} C_{2}^{e}}=\frac{P_{1} C_{1}^{u}}{P_{1} C_{1}^{u}+\frac{1}{1+r} P_{2} C_{2}^{u}}$, and $1-\alpha=\frac{\frac{1}{1+r} P_{2} C_{2}^{e}}{P_{1} C_{1}^{e}+\frac{1}{1+r} P_{2} C_{2}^{e}}=\frac{\frac{1}{1+r} P_{2} C_{2}^{u}}{P_{1} C_{1}^{u}+\frac{1}{1+r} P_{2} C_{2}^{u}}$.

By the calculations in Appendix, the author obtains the following demand functions for consumption baskets: 


$$
\begin{gathered}
C_{1}^{e}=\alpha \frac{W l+\Pi}{P_{1}} \\
C_{2}^{e}=(1+r)(1-\alpha) \frac{W l+\Pi}{P_{2}}, \\
C_{1}^{u}=\alpha \frac{\Pi}{P_{1}}
\end{gathered}
$$

and

$$
C_{2}^{u}=(1+r)(1-\alpha) \frac{\Pi}{P_{2}}
$$

The demand functions for good $z$ of an employed consumer and an unemployed consumer are the following:

$$
\begin{gathered}
c_{1}^{e}(z)=\left(\frac{p_{1}(z)}{P_{1}}\right)^{-\sigma} \frac{\alpha(W l+\Pi)}{P_{1}} \\
c_{2}^{e}(z)=\left(\frac{p_{2}(z)}{P_{2}}\right)^{-\sigma} \frac{(1+r)(1-\alpha)(W l+\Pi)}{P_{2}} \\
c_{1}^{u}(z)=\left(\frac{p_{1}(z)}{P_{1}}\right)^{-\sigma} \frac{\alpha \Pi}{P_{1}}
\end{gathered}
$$

and

$$
c_{2}^{u}(z)=\left(\frac{p_{2}(z)}{P_{2}}\right)^{-\sigma} \frac{(1+r)(1-\alpha) \Pi}{P_{2}}
$$

\subsection{Firm Behaviour}

Let $d_{1}(z)$ be the total demand for good $z$ by younger generation consumers in Period 1. Then,

$$
d_{1}(z)=\left(\frac{p_{1}(z)}{P_{1}}\right)^{-\sigma} \frac{\alpha\left(W L+L_{f} \Pi\right)}{P_{1}}=\left(\frac{p_{1}(z)}{P_{1}}\right)^{-\sigma} \frac{\alpha\left(W L+L_{f} \Pi\right)}{P_{1}}
$$

This is the sum of the demand of employed and unemployed consumers. Similarly, their total demand for good $z$ in Period 2 is written as follows:

$$
d_{2}(z)=\left(\frac{p_{2}(z)}{P_{2}}\right)^{-\sigma} \frac{(1+r)(1-\alpha)\left(W L+L_{f} \Pi\right)}{P_{2}} .
$$

Let $\overline{d_{2}(z)}$ be the demand for good $z$ by the older generation consumers in Period 1. Then,

$$
\overline{d_{2}(z)}=\left(\frac{p_{1}(z)}{P_{1}}\right)^{-\sigma} \frac{(1+r)(1-\alpha)\left(\bar{W} \bar{L}+L_{f} \bar{\Pi}\right)}{P_{1}},
$$


where $\bar{W}, \bar{\Pi}$ and $\bar{L}$ are the nominal wage rate, the profits of firms and the employment, respectively, during the previous period.

Let

$$
M=(1-\alpha)\left(\bar{W} \bar{L}+L_{f} \bar{\Pi}\right) .
$$

Then, the total savings or the total consumption of the older generation consumers, including interest income, is as follows:

$$
(1+r) M=(1+r)(1-\alpha)\left(\bar{W} \bar{L}+L_{f} \bar{\Pi}\right) .
$$

It is the planned consumption that is determined in Period 1 of the older generation consumers. Their demand for good $z$ is written as $\left(\frac{p_{1}(z)}{P_{1}}\right)^{-\sigma} \frac{(1+r) M}{P_{1}}$.

The fiscal spending constitutes the national income as well as the consumptions of the younger and older generations. Let $G$ and $g(z)$ be the fiscal spending and the demand for good $z$ of the government. From calculations in Appendix,

$$
g(z)=\left(\frac{p_{1}(z)}{P_{1}}\right)^{-\sigma} \frac{G}{P_{1}}
$$

The total demand for good $z$ is written as follows:

$$
d(z)=\left(\frac{p_{1}(z)}{P_{1}}\right)^{-\sigma} \frac{Y}{P_{1}},
$$

where $Y$ is the effective demand defined by

$$
Y=\alpha\left(W L+L_{f} \Pi\right)+G+(1+r) M .
$$

The output of firm $z$ is $L y$. In the equilibrium $L y=d(z)$. Then,

$$
\frac{\partial d(z)}{\partial L}=y \text {. }
$$

From Eq. (4)

$$
\frac{\partial p_{1}(z)}{\partial d(z)}=-\frac{p_{1}(z)}{\sigma d(z)}
$$

Thus,

$$
\frac{\partial p_{1}(z)}{\partial L}=-\frac{p_{1}(z) y}{\sigma d(z)}=-\frac{p_{1}(z) y}{\sigma L y} .
$$

The profit of firm $z$ is

$$
\pi(z)=p_{1}(z) L y-L W .
$$

The condition for profit maximization is

$$
\frac{\partial \pi(z)}{\partial L}=p_{1}(z) y-L y \frac{p_{1}(z) y}{\sigma L y}-W=p_{1}(z) y-\frac{p_{1}(z) y}{\sigma}-W=0 .
$$

Therefore, 


$$
p_{1}(z)=\frac{1}{\left(1-\frac{1}{\sigma}\right) y} W
$$

Let $\mu=1 / \sigma$. Then,

$$
p_{1}(z)=\frac{1}{(1-\mu) y} W
$$

This means that the real wage rate is

$$
\omega=(1-\mu) y \text {. }
$$

Since all firms are symmetric,

$$
P_{1}=p_{1}(z)=\frac{1}{(1-\mu) y} W .
$$

\section{BUDGET DEFICIT TO MAINTAIN FULL EMPLOYMENT UNDER ECONOMIC GROWTH}

\subsection{Market Equilibrium}

The (nominal) aggregate supply of the goods equals

$$
W L+L_{f} \Pi=P_{1} L y \text {. }
$$

The (nominal) aggregate demand is

$$
\alpha\left(W L+L_{f} \Pi\right)+G+(1+r) M=\alpha P_{1} L y+G+(1+r) M .
$$

Since they are equal,

$$
P_{1} L y=\alpha P_{1} L y+G+(1+r) M .
$$

In real terms

$$
L y=\frac{G+(1+r) M}{(1-\alpha) P_{1}} .
$$

If $L<L_{f}$, then there is involuntary unemployment. If the government collects a lump-sum tax $T$ from the younger generation consumers, Eq. (5) is rewritten as follows:

$$
P_{1} L y=\alpha\left(P_{1} L y-T\right)+G+(1+r) M .
$$

\subsection{Budget Deficit to Maintain Full Employment}

Let us suppose that up to Period $t$ full employment is achieved. Then,

$$
P_{1}^{t} L_{f} y=\alpha\left(P_{1}^{t} L_{f} y-T^{t}\right)+G^{t}+(1+r) M^{t} .
$$

Superscript $t$ represents the values in Period $t$. In such a steady state with full employment it can be assumed that the price is constant. Then, $\rho=1$. The savings of the younger generation: 


$$
(1-\alpha)\left(P_{1}^{t} L_{f} y-T^{t}\right)=G^{t}-T^{t}+(1+r) M^{t} .
$$

$M^{t}$ is the savings of the younger generation consumers in Period $t-1$ (they are older generation consumers in Period $t)$, and $(1+r) M^{t}$ equals their consumption in Period $t$. In order to maintain full employment with growth by technological progress Eq. (7) must be equal to $\gamma M^{t}$. Therefore,

$$
G^{t}-T^{t}+r M^{t}=(\gamma-1) M^{t} \text {. }
$$

$G^{t}-T^{t}+r M^{t}>0$ when $\gamma>1$. $r M^{t}$ is the interest payments on government bonds. The following proposition has been shown.

Proposition 1. Continuous budget deficit including interest payments on the government bonds is necessary to achieve and maintain full employment when the economy grows at the positive rate by technological progress.

Since the budget deficits must be continuous, it might be better if they were financed by seigniorage rather than government debt. However, the budget deficit excluding interest payments may be negative even under economic growth. Equation (8) is rewritten as follows:

$$
G^{t}-T^{t}=(\gamma-1-r) M^{t}
$$

This means that if the growth rate $\gamma-1$ is smaller than the interest rate $r$, the budget deficit to maintain full employment may be negative. As stated in the Introduction, the budget deficit due to the issuance of government bonds puts pressure on fiscal expenditures in the amount of interest payments. Thus, a budget deficit of the same size due to seigniorage is a more effective use of the budget.

\subsection{Note on Inflation}

In Eq. (7), given $T^{t}$ and $M^{t}$, if the fiscal spending is larger than $G^{t}$, the price is larger than $P_{1}^{t}$ under full employment. Therefore, if the actual budget deficit is larger than the budget deficit necessary and sufficient to maintain full employment in a growing economy, the price of goods will rise. The same conclusion can be drawn for the case where the tax is smaller than $T^{t}$ under given $G^{t}$ and $M^{t}$.

\section{ACHIEVEMENT OF FULL EMPLOYMENT FROM RECESSION}

Let us suppose that a recession with involuntary unemployment is occurring in Period $t-1$ due to insufficient demand, and full employment is achieved in the next period, Period $t$. Let $\widehat{G}^{t}$ and $(1+r) \widehat{M}^{t}$ be the real values of the fiscal spending and the savings of the older generation consumers including interest income. They may be different from their steady state values, $G^{t}$ and $(1+r) M^{t} . T^{t}$ does not change. Then,

$$
P_{1}^{t} L_{f} y=\alpha\left(P_{1}^{t} L_{f} y-T^{t}\right)+\widehat{G}^{t}+(1+r) \widehat{M}^{t} .
$$

Comparing Eq. (7) and Eq. (9) yields 


$$
\hat{G}^{t}-G^{t}=(1+r)\left(M^{t}-\widehat{M}^{t}\right)
$$

This means

$$
\widehat{G}^{t}+r \widehat{M}^{t}-\left(G^{t}+r M^{t}\right)=M^{t}-\widehat{M}^{t} .
$$

Since there is involuntary unemployment in Period $t-1, \widehat{M}^{t}$ is smaller than $M^{t}$ that is the steady state value of the savings of the younger generation in Period $t-1$. Thus,

$$
\widehat{G}^{t}+r \widehat{M}^{t}-\left(G^{t}+r M^{t}\right)>0 .
$$

This means that the extra budget deficit, including the interest payments on government bonds, is necessary to achieve full employment in a period from a sate with involuntary unemployment in the previous period. This extra budget deficit should also be financed by seigniorage not by government bonds because continuous budget deficit after realization of full employment is necessary. The following proposition has been shown.

Proposition 2. To achieve full employment from a state with involuntary unemployment, the extra budget deficit over the steady state value of the budget deficit, including interest payments on the government bonds, is necessary to maintain full employment.

\section{CONCLUSION}

This paper has shown the following results.

1. The continuous budget deficit, including interest payments on the government bonds, is necessary to achieve and maintain full employment when the economy grows at the positive rate by technological progress.

2. To achieve full employment from a state with involuntary unemployment, the extra budget deficit over the steady state value of the budget deficit, including interest payments on the government bonds, is necessary to maintain full employment.

Since the budget deficits must be continuous, it might be better if they were financed by seigniorage rather than government debt.

As stated in the Introduction and discussed in Section 3.2, if the interest rate of the government bonds is larger than the economic growth rate, the budget deficit excluding interest payments which is necessary and sufficient to maintain full employment may be negative. However, interest on government bonds can be regarded as a kind of benefit policy for bondholders, and a sense of unfairness cannot be avoided. When government bonds are issued for budget deficits, only the amount of interest paid to bondholders will be borne by the public. In order to use fiscal expenditure effectively, it is better to use seigniorage instead of government bonds. 


\section{APPENDIX: MAXIMIZATION FOR CONSUMERS AND THE GOVERNMENT}

The utility function of an employed consumer is

$$
u^{e}=u\left(C_{1}^{e}, C_{2}^{e}\right)
$$

His consumption baskets are

$$
C_{i}^{e}=\left(\int_{0}^{1} c_{i}^{e}(z)^{\frac{\sigma-1}{\sigma}} d z\right)^{\frac{\sigma}{\sigma-1}}, i=1,2
$$

His budget constraint is

$$
\int_{0}^{1} p_{1}(z) c_{1}^{e}(z) d z+\frac{1}{1+r} \int_{0}^{1} p_{2}(z) c_{2}^{e}(z) d z=W l+\Pi .
$$

The utility function of an unemployed consumer is

$$
u^{u}=u\left(C_{1}^{u}, C_{2}^{u}\right) .
$$

His consumption baskets are

$$
C_{i}^{u}=\left(\int_{0}^{1} c_{i}^{u}(z)^{\frac{\sigma-1}{\sigma}} d z\right)^{\frac{\sigma}{\sigma-1}}, i=1,2
$$

His budget constraint is

$$
\int_{0}^{1} p_{1}(z) c_{1}^{u}(z) d z+\frac{1}{1+r} \int_{0}^{1} p_{2}(z) c_{2}^{u}(z) d z=\Pi .
$$

The conditions for utility maximization for an employed consumer are

$$
\frac{\partial u^{e}}{\partial c_{1}^{e}}\left(\int_{0}^{1} c_{1}^{e}(z)^{\frac{\sigma-1}{\sigma}} d z\right)^{\frac{1}{\sigma-1}} c_{1}^{e}(z)^{\frac{-1}{\sigma}}-\lambda p_{1}(z)=0,
$$

and

$$
\frac{\partial u^{e}}{\partial C_{2}^{e}}\left(\int_{0}^{1} c_{2}^{e}(z)^{\frac{\sigma-1}{\sigma}} d z\right)^{\frac{1}{\sigma-1}} c_{2}^{e}(z)^{\frac{-1}{\sigma}}-\lambda \frac{1}{1+r} p_{2}(z)=0 .
$$

$\lambda$ is the Lagrange multiplier. From them

$$
\frac{\partial u^{e}}{\partial C_{1}^{e}}\left(\int_{0}^{1} c_{1}^{e}(z)^{\frac{\sigma-1}{\sigma}} d z\right)^{\frac{1}{\sigma-1}} c_{1}^{e}(z)^{\frac{\sigma-1}{\sigma}}-\lambda p_{1}(z) c_{1}^{e}(z)=0
$$

and

$$
\frac{\partial u^{e}}{\partial C_{2}^{e}}\left(\int_{0}^{1} c_{2}^{e}(z)^{\frac{\sigma-1}{\sigma}} d z\right)^{\frac{1}{\sigma-1}} c_{2}^{e}(z)^{\frac{\sigma-1}{\sigma}}-\lambda \frac{1}{1+r} p_{2}(z) c_{2}^{e}(z)=0 .
$$

Integrating them yields 


$$
\frac{\partial u^{e}}{\partial C_{1}^{e}}\left(\int_{0}^{1} c_{1}^{e}(z)^{\frac{\sigma-1}{\sigma}} d z\right)^{\frac{1}{\sigma-1}} \int_{0}^{1} c_{1}^{e}(z)^{\frac{\sigma-1}{\sigma}} d z-\lambda \int_{0}^{1} p_{1}(z) c_{1}^{e}(z) d z=0,
$$

and

$\frac{\partial u^{e}}{\partial C_{2}^{e}}\left(\int_{0}^{1} c_{2}^{e}(z)^{\frac{\sigma-1}{\sigma}} d z\right)^{\frac{1}{\sigma-1}} \int_{0}^{1} c_{2}^{e}(z)^{\frac{\sigma-1}{\sigma}} d z-\lambda \frac{1}{1+r} \int_{0}^{1} p_{2}(z) c_{2}^{e}(z) d z=0$.

These mean

$$
\frac{\partial u^{e}}{\partial C_{1}^{e}} C_{1}^{e}-\lambda \int_{0}^{1} p_{1}(z) c_{1}^{e}(z) d z=0
$$

and

$$
\frac{\partial u^{e}}{\partial C_{2}^{e}} C_{2}^{e}-\lambda \frac{1}{1+r} \int_{0}^{1} p_{2}(z) c_{2}^{e}(z) d z=0 .
$$

Again Eq. (10) and Eq. (11) mean

$$
\left(\frac{\partial u^{e}}{\partial C_{1}^{e}}\right)^{1-\sigma}\left(\int_{0}^{1} c_{1}^{e}(z)^{\frac{\sigma-1}{\sigma}} d z\right)^{\frac{1-\sigma}{\sigma-1}} c_{1}^{e}(z)^{\frac{\sigma-1}{\sigma}}=\lambda^{1-\sigma} p_{1}(z)^{1-\sigma}
$$

and

$$
\left(\frac{\partial u^{e}}{\partial C_{2}^{e}}\right)^{1-\sigma}\left(\int_{0}^{1} c_{2}^{e}(z)^{\frac{\sigma-1}{\sigma}} d z\right)^{\frac{1-\sigma}{\sigma-1}} c_{2}^{e}(z)^{\frac{\sigma-1}{\sigma}}=\lambda^{1-\sigma}\left(\frac{1}{1+r}\right)^{1-\sigma} p_{2}(z)^{1-\sigma}
$$

From them,

$$
\left(\frac{\partial u^{e}}{\partial C_{1}^{e}}\right)^{1-\sigma}\left(\int_{0}^{1} c_{1}^{e}(z)^{\frac{\sigma-1}{\sigma}} d z\right)^{-1} \int_{0}^{1} c_{1}^{e}(z)^{\frac{\sigma-1}{\sigma}} d z=\lambda^{1-\sigma} \int_{0}^{1} p_{1}(z)^{1-\sigma} d z
$$

and

$$
\begin{array}{r}
\left(\frac{\partial u^{e}}{\partial C_{2}^{e}}\right)^{1-\sigma}\left(\int_{0}^{1} c_{2}^{e}(z)^{\frac{\sigma-1}{\sigma}} d z\right)^{-1} \int_{0}^{1} c_{2}^{e}(z)^{\frac{\sigma-1}{\sigma}} d z \\
=\lambda^{1-\sigma}\left(\frac{1}{1+r}\right)^{1-\sigma} \int_{0}^{1} p_{2}(z)^{1-\sigma} d z
\end{array}
$$

These imply

$$
\frac{\partial u^{e}}{\partial C_{1}^{e}}=\lambda\left(\int_{0}^{1} p_{1}(z)^{1-\sigma} d z\right)^{\frac{1}{1-\sigma}}=\lambda P_{1}
$$

and 


$$
\frac{\partial u^{e}}{\partial C_{2}^{e}}=\lambda \frac{1}{1+r}\left(\int_{0}^{1} p_{2}(z)^{1-\sigma} d z\right)^{\frac{1}{1-\sigma}}=\lambda \frac{1}{1+r} P_{2} .
$$

Therefore,

$$
P_{1} C_{1}^{e}=\int_{0}^{1} p_{1}(z) c_{1}^{e}(z) d z
$$

and

$$
P_{2} C_{2}^{e}=\int_{0}^{1} p_{2}(z) c_{2}^{e}(z) d z
$$

Let

$$
\alpha=\frac{P_{1} C_{1}^{e}}{P_{1} C_{1}^{e}+\frac{1}{1+r} P_{2} C_{2}^{e}}, \quad 1-\alpha=\frac{\frac{1}{1+r} P_{2} C_{2}^{e}}{P_{1} C_{1}^{e}+\frac{1}{1+r} P_{2} C_{2}^{e}}
$$

Since the utility function is homothetic, $\alpha$ is determined by the relative price $\frac{P_{1}}{P_{2}}$ and the interest rate $r$, and does not depend on the income of consumers. From these analyses the demand functions of an employed consumer for the consumption baskets are obtained as follows:

$$
C_{1}^{e}=\alpha \frac{W l+\Pi}{P_{1}}, \quad C_{2}^{e}=(1-\alpha)(1+r) \frac{W l+\Pi}{P_{2}} .
$$

By similar calculations, the demand functions of an unemployed consumer for the consumption baskets are

$$
C_{1}^{u}=\alpha \frac{\Pi}{P_{1}}, \quad C_{2}^{u}=(1-\alpha)(1+r) \frac{\Pi}{P_{2}} .
$$

Eq. (10) and Eq. (11) also imply

$$
\left(\int_{0}^{1} c_{1}^{e}(z)^{\frac{\sigma-1}{\sigma}} d z\right)^{\frac{\sigma}{\sigma-1}} c_{1}^{e}(z)^{-1}=C_{1}^{e} c_{1}^{e}(z)^{-1}=\left(\frac{p_{1}(z)}{P_{1}}\right)^{\sigma},
$$

and

$$
\left(\int_{0}^{1} c_{2}^{e}(z)^{\frac{\sigma-1}{\sigma}} d z\right)^{\frac{\sigma}{\sigma-1}} c_{2}^{e}(z)^{-1}=C_{2}^{e} c_{2}^{e}(z)^{-1}=\left(\frac{p_{2}(z)}{P_{2}}\right)^{\sigma} .
$$

From them the demand functions for $\operatorname{good} z$ are as follows:

$$
c_{1}^{e}(z)=\left(\frac{p_{1}(z)}{P_{1}}\right)^{-\sigma} \alpha \frac{W l+\Pi}{P_{1}},
$$

and 


$$
c_{2}^{e}(z)=\left(\frac{p_{2}(z)}{P_{2}}\right)^{-\sigma}(1-\alpha)(1+r) \frac{W l+\Pi}{P_{2}} .
$$

Similarly for an unemployed consumers, the demand functions are

$$
c_{1}^{u}(z)=\left(\frac{p_{1}(z)}{P_{1}}\right)^{-\sigma} \alpha \frac{\Pi}{P_{1}}
$$

and

$$
c_{2}^{u}(z)=\left(\frac{p_{2}(z)}{P_{2}}\right)^{-\sigma}(1-\alpha)(1+r) \frac{\Pi}{P_{2}} .
$$

The government determines $g(z)$ for each $z$ to maximise

$$
\mathcal{G}=\left(\int_{0}^{1} g(z)^{\frac{\sigma-1}{\sigma}} d z\right)^{\frac{\sigma}{\sigma-1}}
$$

subject to

$$
\int_{0}^{1} p_{1}(z) g(z) d z=G
$$

Let $\lambda_{g}$ be the Lagrange multiplier. The condition for maximization is

$$
\left(\int_{0}^{1} g(z)^{\frac{\sigma-1}{\sigma}} d z\right)^{\frac{1}{\sigma-1}} g(z)^{\frac{-1}{\sigma}}-\lambda_{g} p_{1}(z)=0 .
$$

From this

$$
\left(\int_{0}^{1} g(z)^{\frac{\sigma-1}{\sigma}} d z\right)^{\frac{1}{\sigma-1}} \int_{0}^{1} g(z)^{\frac{\sigma-1}{\sigma}} d z=\mathcal{G}=\lambda_{g} \int_{0}^{1} p_{1}(z) g(z) d z=\lambda_{g} G .
$$

From Eq. (12)

$$
\left(\int_{0}^{1} g(z)^{\frac{\sigma-1}{\sigma}} d z\right)^{-1} \int_{0}^{1} g(z)^{\frac{\sigma-1}{\sigma}} d z=\lambda_{g}^{1-\sigma} \int_{0}^{1} p_{1}(z)^{1-\sigma} d z=1
$$

This means

$$
\lambda_{g}=\frac{1}{\left(\int_{0}^{1} p_{1}(z)^{1-\sigma} d z\right)^{\frac{1}{1-\sigma}}}=\frac{1}{P_{1}}
$$

Substituting this into Eq. (12) yields

$$
\left(\int_{0}^{1} g(z)^{\frac{\sigma-1}{\sigma}} d z\right)^{\frac{\sigma}{\sigma-1}} g(z)^{-1}=\frac{G}{P_{1}} g(z)^{-1}=\left(\frac{p_{1}(z)}{P_{1}}\right)^{\sigma} .
$$

Then, the demand function of the government is obtained as follows: 


$$
g(z)=\left(\frac{p_{1}(z)}{P_{1}}\right)^{-\sigma} \frac{G}{P_{1}} .
$$

\section{ACKNOWLEDGEMENT}

The authors wish to thank the editor of this journal and the anonymous reviewers for comments on an earlier version of this paper. The research has been supported by JSPS KAKENHI Grant No. 18 K01594 in Japan.

\section{REFERENCES}

Hogan, T. L. (2021). Review of Stephanie Kelton's the Deficit Myth. AIER Sound Money Project Working Paper No. 2021-5. https://papers.ssrn.com/sol3/papers.cfm?abstract_id=3767562

Kelton, S. (2020). The Deficit Myth: Modern monetary theory and the birth of the people's economy. Public Affairs.

Lerner, A. P. (1943). Functional finance and the federal debt. Social Research, 10, 38-51.

Lerner, A. P. (1944). The economics of control: Principles of welfare economics. Macmillan.

Mitchell, W., Wray, L. R., \& Watts, M. (2019). Macroeconomics. Red Globe Press.

Mochizuki, S. (2020). A book understanding MMT (in Japanese, MMT ga yokuwakaru hon). Shuwa System.

Morinaga, K. (2020). MMT will save Japan (in Japanese, MMT ga nihon wo sukuu). Takarajimasha.

Nakano, A. (2020). A book to understand the key points of MMT (in Japanese, MMT no pointo ga yokuwakaru hon), Shuwa System.

Otaki, M. (2007). The dynamically extended Keynesian cross and the welfare-improving fiscal policy. Economics Letters, 96, 23-29. https://doi.org/10.1016/j.econlet.2006.12.005

Otaki, M. (2009). A welfare economics foundation for the full-employment policy. Economics Letters, 102(1), 1-3. https://doi.org/10.1016/j.econlet.2008.08.003

Otaki, M. (2012). A Keynesian endogenous growth theory with a rigorous microeconomic foundation. Theoretical Economics Letters, 2(4), 365-368. https://doi.org/10.4236/tel.2012.24067

Otaki, M. (2013). On the endogenous sustainability of economic growth: Why is the scale of government enlarged? Theoretical Economics Letters, 3(3), 159-163. https://doi.org/10.4236/tel.2013.33026

Otaki, M., \& Tamura, M. (2013). Monetary growth theory under perfect and monopolistic competitions. Theoretical Economics Letters, 3(4), 216-219. https://doi.org/10.4236/tel.2013.34036

Otaki, M. (2015a). Keynesian economics and price theory: Re-orientation of a theory of monetary economy. Springer. https://doi.org/10.1007/978-4-431-55345-8

Otaki, M. (2015b). Public debt as a burden on the future generation: A Keynesian approach. Theoretical Economics Letters, 5(5), 651-658. https://doi.org/10.4236/tel.2015.55076

Park, S. (2020). The fallacy of fiscal collapse (in Japanese, Zaisei hatanron no ayamari). Seitosha.

Shimakura, G. (2019). What is MMT? (in Japanese, MMT towa nanika), Kadokawa Shinsho.

Tanaka, Y. (2020). Involuntary unemployment with indivisible labor supply under perfect competition. Economics Bulletin, 40(3), 1914-1923. http://www.accessecon.com/Pubs/EB/2020/Volume40/EB-20-V40-I3-P165.pdf

Tanaka, Y. (2022). Debt to GDP ratio from the perspective of MMT. Business Management and Strategy, 13(1), 1-12. https://doi.org/10.5296/bms.v13i1.19353

Wray, L. R. (2015). Modern money theory: A primer on macroeconomics for sovereign monetary systems (2nd ed.). Palgrave Macmillan. 


\section{AUTHOR'S SHORT BIOGRAPHY}

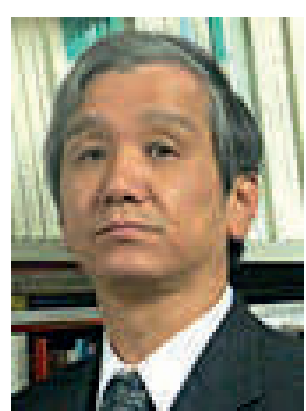

Yasuhito Tanaka graduated from the Faculty of Engineering, University of Kyoto in Japan in 1976, and completed the Graduate School of Economics, University of Tokyo in Japan in 1986, and received his $\mathrm{PhD}$ in Economics in 2000 .

He has been teaching microeconomics and international economics at Doshisha University in Kyoto, Japan, since 2003. He has been working mainly on oligopoly theory and game theory, but recently he has been interested in macroeconomic issues.

E-mail: yatanaka@mail.doshisha.ac.jp

ORCID iD: https://orcid.org/0000-0003-1435-462X 